\title{
Antimicrobial Stewardship: From Bedside to Theory. Thirteen Examples of Old and More Recent Strategies from Everyday Clinical Practice
}

\author{
Stefano Di Bella ${ }^{1, *(\mathbb{D}}$, Bojana Beović ${ }^{2}$, Massimiliano Fabbiani ${ }^{3}\left(\mathbb{D}\right.$, Michael Valentini ${ }^{4}$ and \\ Roberto Luzzati ${ }^{1}$ (D) \\ 1 Department of Medical, Surgical and Health Sciences, Trieste University, 34127 Trieste, Italy; \\ roberto.luzzati@asugi.sanita.fvg.it \\ 2 Department of Infectious Diseases, University Medical Centre Ljubljana, 1000 Ljubljana, Slovenia; \\ bojana.beovic@kclj.si \\ 3 Infectious Disease Unit, Azienda Ospedaliero-Universitaria Senese, 53100 Siena, Italy; \\ massimiliano.fabbiani@gmail.com \\ 4 Azienda Sanitaria Universitaria Giuliano Isontina, 34128 Trieste, Italy; michael.valentini@asugi.sanita.fvg.it \\ * Correspondence: stefano932@gmail.com
}

Received: 10 June 2020; Accepted: 8 July 2020; Published: 10 July 2020

\begin{abstract}
Antimicrobial stewardship" is a strategy that promotes the responsible use of antimicrobials. The objective of this paper is to focus on consolidated and more recent improvements in clinical strategies that should be adopted in hospitalized patients to ameliorate their infectious diseases' outcome and to reduce the antibiotic resistance risk through judicious use of antibiotics. We present 13 common clinical scenarios, the respective suggested interventions and the explanations of the supporting evidence, in order to help clinicians in their decision-making process. Strategies including the choice of antibiotic and dose optimization, antibiotic spectrum narrowing (de-escalation), shortening of duration, shift to oral route or outpatient parenteral antibiotic (including elastomeric pumps), and biomarkers are described and discussed.
\end{abstract}

Keywords: antimicrobial stewardship; anti-bacterial agents; outpatients; antibiotic optimization; antibiotic policy

\section{Introduction}

Bacteria are continuously evolving and antibiotic resistances are significantly increasing, with 33,000 people in Europe, 35,000 in United States and >38,000 in Southeast Asia dying each year from antibiotic-resistant infections [1-3]. These numbers are expected to dramatically increase in the near future, with a worldwide estimate of 10 million deaths per year in 2050 due to antimicrobial resistance [4]. To limit the spread of antimicrobial resistance, reduce its related death and lower healthcare costs sustained for the management of drug resistant infections, the implementation of antimicrobial stewardship (AMS) programs has been advocated for several years. Since $20-50 \%$ of all antibiotics prescribed in acute-care hospital are either unnecessary or inappropriate [5,6], AMS has the potential capability to improve patient outcomes, reduce the incidence of antibiotic-related adverse events, curb antibiotic resistance and optimize resource utilization [7].

Despite AMS currently being an extensively used medical term, it lacks a universally endorsed definition. Many doctors believe that AMS sums up and embodies what both infectious diseases physicians and generally all antibiotic prescribers should do. Recently, Dyar et al. tried to provide a definition for AMS: the authors suggested "viewing AMS as a strategy, a coherent set of actions which promote using antimicrobials responsibly", stressing the continuous need for "responsible use" to be 
defined and translated into context-specific and time-specific actions [8]. Several actions for AMS have been advocated and they include interventions both at a strategical level (e.g., education, restrictive and persuasive prescriptions) and at a patient level. For the latter, general principles have been extensively delineated, including recommendations on treating infections but not colonizations, implementing the appropriate use of antibiotics, narrowing broad-spectrum therapy, and selecting antibiotics with low Clostridioides difficile potential [9]. However, practical indications on how to implement AMS principles while taking care of individual patients at bedside are often lacking.

In light of these data and the given lack of pragmatism we found in several AMS papers, we tried to furnish common examples of clinical interventions that could help in both better understanding the AMS interventions by primary teams and improving the prescriptions themselves. On the basis of principles reported by guidelines and the current literature [7], and also on the basis of bedside clinical experience, we selected the following example scenarios: optimizing antibiotic dosing strategies, narrowing the antibiotic spectrum, avoiding unnecessary double anaerobic coverage, shift to an oral antibiotic regimen, shortening antibiotic duration, de-hospitalizing patients, approaching extended spectrum beta lactamases (ESBL) or carbapenem-resistant Enterobacteriaceae (CRE) urinary tract infections, using biomarkers and urinary antigens as stewardship tools, re-using old antibiotics, antibiotic allergy de-labelling (Figure 1). The choice of these clinical scenarios took into account the existing acute care antibiotic bundles [10] and what we believed to be significant situations faced during everyday clinical practice.

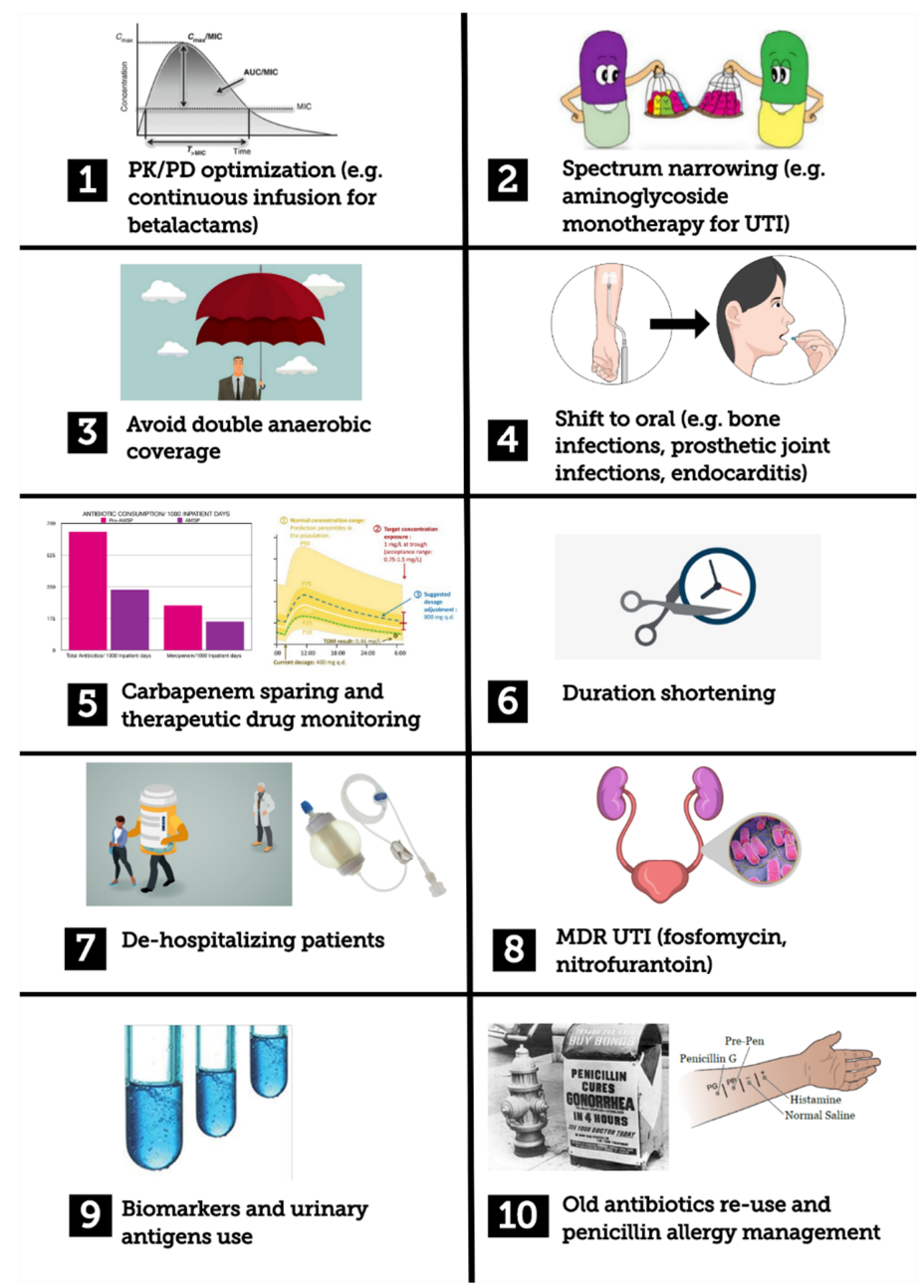

Figure 1. Graphical summary of stewardship interventions described in the manuscript. MDR: multidrug resistant; PK/PD: pharmacokinetic/pharmacodynamics; UTI: urinary tract infection 


\section{Thirteen Common Scenarios of Clinical AMS Strategies}

\subsection{Antibiotic Dosing Strategies}

\subsubsection{Example 1}

A 55-year old male patient with acute myeloid leukemia was treated with chemotherapy. He developed febrile neutropenia and sepsis. He had no central vascular catheter nor other obvious infectious focus. After blood cultures were drawn, an empiric therapy with intravenous piperacillin/tazobactam $4.5 \mathrm{~g}$ every $8 \mathrm{~h}$ was commenced by the hematologist.

\subsubsection{Intervention 1}

Optimization of therapy was carried out by increasing the daily dose of piperacillin/tazobactam up to $18 \mathrm{~g}$ daily and administration of the antibiotic by continuous infusion.

\subsubsection{Comment 1}

Neutropenic patients are at risk of severe infections especially due to Gram-negative organisms such as Pseudomonas aeruginosa, therefore the "anti-pseudomonas dosage" should be used (18 instead of $13.5 \mathrm{~g}$ ). In addition, the literature data support the administration of beta-lactam antibiotics through continuous infusion for both increasing antibacterial activity and reducing sepsis-associated mortality [11].

\subsection{Narrowing the Antibiotic Spectrum (Reducing the Induction of Multidrug-Resistant Bacteria and} Clostridioides Difficile Infection)

\subsubsection{Example 2}

A 49-year old female obese patient, receiving insulin for diabetes mellitus, was admitted to the intensive care unit for septic shock and left leg ulcerative cellulitis. Empirical therapy with intravenous ceftriaxone was commenced. Two blood cultures yielded Streptococcus pyogenes.

\subsubsection{Intervention 2}

Shift from intravenous ceftriaxone to intravenous penicillin G.

\subsubsection{Comment 2}

Antibiotic therapy is a risk factor for developing infections from extended spectrum beta lactamases (ESBL)-producing bacteria and C. difficile. C. difficile has become the main cause of nosocomial infections in the western world [12]. Third generation cephalosporins are a strong risk factors for both extended spectrum beta-lactamases (ESBL)-producing microorganisms and C. difficile emergence [13,14]. In Example 2, shifting from ceftriaxone to penicillin $\mathrm{G}$ allows for narrowing the spectrum with a potent molecule but is poorly active against Gram negatives, thus potentially reducing the risk of developing ESBL and/or C. difficile infection.

\subsection{Unnecessary Double Anaerobic Coverage}

\subsubsection{Example 3}

A 67-year old male underwent a recent hemicolectomy for left colon cancer. Four days after surgery, he developed fever, tachypnea and altered mental status. No intra-abdominal collections were found by computed tomography scan. Empirical therapy with piperacillin/tazobactam and metronidazole was commenced. Following two days of antibiotic therapy, the patient clinically improved. No microbial growth was demonstrated in blood cultures. 


\subsubsection{Intervention 3}

Maintaining piperacillin/tazobactam while discontinuing metronidazole.

\subsubsection{Comment 3}

Another frequently faced situation is the double anaerobic coverage in patients with intra-abdominal infections. Unnecessary double anaerobic coverage has been related to increased hospital costs, risk of drug-resistant pathogen acquisition, and the development of adverse reactions [15]. Almost half of the prescriptions of metronidazole in combination with other anti-anaerobic agents are unnecessary [15-17]. Since double anti-anaerobic coverage is a common scenario, it represents a relevant issue to be addressed by AMS efforts. The main antimicrobials with good anti-anaerobic coverage are shown in Table 1. Obtaining data from local antimicrobial susceptibility of anaerobes would be desirable prior to taking clinical decisions in this field.

Table 1. Commonly used antibiotics with anaerobic coverage.

\begin{tabular}{ccc}
\hline & Degree of Activity & \\
\hline Antibiotics with Anaerobic Coverage & Beta-Lactamase Producing Anaerobes & Other Anaerobes \\
\hline Amoxicillin/clavulanate & +++ & +++ \\
Cefoxitin & ++ & +++ \\
Chloramphenicol & +++ & +++ \\
Clindamycin & ++ & +++ \\
Ertapenem & +++ & +++ \\
Imipenem & +++ & +++ \\
Meropenem & +++ & +++ \\
Metronidazole & +++ & +++ \\
Moxifloxacin & ++ & ++ \\
Penicillin & 0 & +++ \\
Piperacillin/tazobactam & +++ & +++ \\
Ticarcillin & + & +++ \\
Tigecycline & ++ & +++ \\
\hline
\end{tabular}

Adapted from Brook et al. [15].

\subsection{Shift to Oral Antibiotic Regimen}

\subsubsection{Example 4}

A 39-year old female patient had native mitral valve endocarditis due to Streptococcus mitis showing penicillin minimum inhibitory concentration (MIC) $\leq 0.12 \mu \mathrm{g} / \mathrm{mL}$. Her vital signs were stable and within normal limits. The echocardiographic examination showed mitral valve prolapse, evidence of an $8 \times 13 \mathrm{~mm}$ vegetation, but no valve regurgitation or other abnormalities. No need for cardiac surgery was established. Targeted antibiotic therapy with ceftriaxone was started.

\subsubsection{Intervention 4}

Fever disappeared at $36 \mathrm{~h}$ of antibiotic therapy and the patient's vital signs remained stable. Therefore, after 10 days, antibiotic treatment was shifted from intravenous to oral regimen with amoxicillin $1 \mathrm{~g}$ orally every $6 \mathrm{~h}+$ rifampin $600 \mathrm{mg}$ orally every $12 \mathrm{~h}$.

\subsubsection{Comment 4}

There is evidence that a shift from intravenous to oral antibiotic regimens in stable patients with left sided endocarditis is non-inferior to continued intravenous antibiotic treatment. The Danish trial published in 2018 included endocarditis due to Streptococcus spp., Enterococcus faecalis, Staphylococcus aureus or coagulase-negative staphylococci [18]. Patients with signs of abscess formation or valve abnormalities requiring surgery were excluded. The primary outcome was a composite of all-cause mortality, unplanned cardiac surgery, embolic events, or relapse of bacteremia with the 
primary pathogen. Patients were treated for at least 10 days (median 17 days) with intravenous therapy and then shifted to an oral regimen (Table 2) or maintained in intravenous therapy according to randomization. The primary composite outcome occurred in $12 \%$ of the intravenously treated group vs $9 \%$ of the orally treated group $(p=0.4)$ [18]. Prudence and commons sense are always welcome when facing endocarditis in order to not miss exclusion criteria (or complications) contraindicating the shift to oral antibiotic therapy.

Table 2. Oral antibiotic regimens adopted in the Danish trial [18].

\begin{tabular}{|c|c|}
\hline $\begin{array}{l}\text { Penicillin and methicillin sensitive S. aureus and } \\
\text { coagulase-negative staphylococci }\end{array}$ & $\begin{array}{l}\text { amoxicillin } 1 \mathrm{~g} \mathrm{q} 6 \mathrm{~h} \text { and fusidic acid } 750 \mathrm{mg} \mathrm{q} 12 \mathrm{~h} \\
\text { amoxicillin } 1 \mathrm{~g} \mathrm{q} 6 \mathrm{~h} \text { and rifampicin } 600 \mathrm{mg} \mathrm{q} 12 \mathrm{~h} \\
\text { linezolid } 600 \mathrm{mg} \mathrm{q} 12 \mathrm{~h} \text { and fusidic acid } 750 \mathrm{mg} \text { q12 } \mathrm{h} \\
\text { linezolid } 600 \mathrm{mg} \mathrm{q} 12 \mathrm{~h} \text { and rifampicin } 600 \mathrm{mg} \mathrm{q} 12 \mathrm{~h}\end{array}$ \\
\hline $\begin{array}{l}\text { Methicillin sensitive S. aureus and coagulase-negative } \\
\text { staphylococci }\end{array}$ & $\begin{array}{l}\text { dicloxacillin } 1 \mathrm{~g} \mathrm{q} 6 \mathrm{~h} \text { and fusidic acid } 750 \mathrm{mg} \mathrm{q} 12 \mathrm{~h} \\
\text { dicloxacillin } 1 \mathrm{~g} \mathrm{q} 6 \mathrm{~h} \text { and rifampicin } 600 \mathrm{mg} \text { q12 } \mathrm{h} \\
\text { linezolid } 600 \mathrm{mg} \mathrm{q} 12 \mathrm{~h} \text { and fucidic acid } 750 \mathrm{mg} \mathrm{q} 12 \mathrm{~h} \\
\text { linezolid } 600 \mathrm{mg} \mathrm{q} 12 \mathrm{~h} \text { and rifampicin } 600 \mathrm{mg} \mathrm{q} 12 \mathrm{~h}\end{array}$ \\
\hline Methicillin resistant coagulase-negative staphylococci & $\begin{array}{l}\text { linezolid } 600 \mathrm{mg} \mathrm{q} 12 \mathrm{~h} \text { and fusidic acid } 750 \mathrm{mg} \mathrm{q} 12 \mathrm{~h} \\
\text { linezolid } 600 \mathrm{mg} \mathrm{q12} \mathrm{h} \text { and rifampicin } 600 \mathrm{mg} \text { q12 h }\end{array}$ \\
\hline E. faecalis & $\begin{array}{l}\text { amoxicillin } 1 \mathrm{~g} \mathrm{q} 6 \mathrm{~h} \text { and rifampicin } 600 \mathrm{mg} \mathrm{q} 12 \mathrm{~h} \\
\text { amoxicillin } 1 \mathrm{~g} \mathrm{q} 6 \mathrm{~h} \text { and moxifloxacin } 400 \mathrm{mg} \mathrm{q} 24 \mathrm{~h} \\
\text { linezolid } 600 \mathrm{mg} \mathrm{q} 12 \mathrm{~h} \text { and rifampicin } 600 \mathrm{mg} \mathrm{q} 12 \mathrm{~h} \\
\text { linezolid } 600 \mathrm{mg} \mathrm{q} 12 \mathrm{~h} \text { and moxifloxacin } 400 \mathrm{mg} \mathrm{q} 24 \mathrm{~h}\end{array}$ \\
\hline Streptococci with a penicillin MIC $<1 \mathrm{mg} / \mathrm{L}$ & $\begin{array}{l}\text { amoxicillin } 1 \mathrm{~g} \mathrm{q} 6 \mathrm{~h} \text { and rifampicin } 600 \mathrm{mg} \mathrm{q} 12 \mathrm{~h} \\
\text { linezolid } 600 \mathrm{mg} \mathrm{q} 12 \mathrm{~h} \text { and rifampicin } 600 \mathrm{mg} \mathrm{q} 12 \mathrm{~h} \\
\text { linezolid } 600 \mathrm{mg} \mathrm{q} 12 \mathrm{~h} \text { and moxifloxacin } 400 \mathrm{mg} \mathrm{q} 24 \mathrm{~h}\end{array}$ \\
\hline Streptococci with penicillin MIC $\geq 1 \mathrm{mg} / \mathrm{L}$ & $\begin{array}{l}\text { linezolid } 600 \mathrm{mg} \mathrm{q} 12 \mathrm{~h} \text { and rifampicin } 600 \mathrm{mg} \mathrm{q} 12 \mathrm{~h} \\
\text { moxifloxacin } 400 \mathrm{mg} \text { q } 24 \mathrm{~h} \text { and rifampicin } 600 \mathrm{mg} \text { q12 h } \\
\text { moxifloxacin } 400 \mathrm{mg} \mathrm{q} 24 \mathrm{~h} \text { and clindamycin } 600 \mathrm{mg} \mathrm{q} 8 \mathrm{~h}\end{array}$ \\
\hline
\end{tabular}

MIC: minimal inhibitory concentration.

\subsubsection{Example 5}

A 55-year old man with persistent fever and lumbar pain was diagnosed with lumbar vertebral osteomyelitis (L4-L5). No neurological abnormalities were found. Diagnosis of probable vertebral osteomyelitis (L4-L5) was obtained by magnetic resonance imaging. The tissue culture from bone biopsy grew methicillin-susceptible S. aureus. Intravenous therapy with oxacillin 2 g every $4 \mathrm{~h}$ was commenced.

\subsubsection{Intervention 5}

After 7 days, the intravenous antibiotic therapy was changed to an oral regimen including levofloxacin $500 \mathrm{mg}$ every $12 \mathrm{~h}$ plus rifampicin $450 \mathrm{mg}$ every $12 \mathrm{~h}$.

\subsubsection{Comment 5}

The shift from intravenous to oral antibiotic therapy in bone and joint infections has been associated with a shorter length of hospital stay and fewer complications. In the trial by Li et al. published in 2019 , there were no differences in terms of treatment failure in patients with bone or joint infection shifted to oral therapy within 7 days after surgery (or, if the infection was being managed without surgery, within 7 days after the start of antibiotic treatment) vs those who continued intravenous antibiotic treatment [19]. In fact, treatment failure occurred in $14.6 \%$ of the intravenous group and $13.2 \%$ of the oral group. No difference in serious adverse events between the two groups was noticed, but catheter complications were more common in the intravenous group (9.4\% vs 1\%) [19]. A shift from intravenous to oral administration turns to be one of the main topics of AMS. Indeed, this policy 
allows the removal of vascular catheters lowering catheter-associated complications and encouraging prompt discharge improving patients' quality of life and reducing health-care costs.

\subsection{Shortening Antibiotic Duration}

\subsubsection{Example 6}

Bacteremic urosepsis due to Escherichia coli was diagnosed in a 65-year-old male with an indwelling urinary catheter for benign prostate hyperplasia. The patient developed fever and chills without other symptoms; his vital signs were stable and within normal limits. Bacteremic urosepsis due to E. coli was diagnosed and the urinary catheter was promptly replaced, and intravenous antibiotic therapy with ceftriaxone was administered, leading to defervescence, and the fever disappeared after $48 \mathrm{~h}$ of treatment.

\subsubsection{Intervention 6}

Stop antibiotic therapy after 7 days of treatment.

\subsubsection{Comment 6}

A recent trial compared a 7-day vs 14-day course of antibiotic therapy for Gram-negative bacteremias. Patients who were afebrile and hemodynamically stable for at least $48 \mathrm{~h}$ were randomized in two arms to receive 7 or 14 days of intravenous antibiotics. The primary outcome at 90 days was a composite of all-cause mortality, relapse, suppurative, or distant complications, and readmission or extended hospitalization ( $>14$ days). Patients with uncontrolled source of infection were excluded, as well as neutropenic, transplanted or HIV-seropositive. There were no significant differences in the primary outcome between the two groups [20].

\subsubsection{Example 7}

A diabetic 70-year-old female was diagnosed with native joint arthritis of her left knee. A synovial fluid culture grew methicillin-susceptible S. aureus. Intravenous oxacillin was commenced and surgical drainage was performed.

\subsubsection{Intervention 7}

Stop antibiotic therapy after a 2-week course of therapy following successful surgical drainage.

\subsubsection{Comment 7}

A trial published in 2019 compared 77 patients treated with a 2-week course with 77 patients treated with 4-week course of antibiotic therapy [20]. The week count was considered after surgical drainage (episodes without surgical lavage were excluded). A minimal follow-up of 2 months was ensured. No difference in cure rate, recurrences and sequelae was found between the two groups [21]. Nowadays, it is possible to shorten the duration of antibiotic therapy even for other common indications, including community-acquired pneumonia (5-7 days) [22,23], ventilator-associated pneumonia (VAP) (8 days) [24], uncomplicated pyelonephritis (5-7 days if treated with a fluoroquinolone) [25], complicated intra-abdominal infections (5 days after adequate source control) [26]. Shorter therapy duration was found to be associated with the emergence of fewer $(-20 \%)$ multidrug resistant pathogens [24].

\subsection{De-Hospitalizing Patients}

\subsubsection{Example 8}

A 66-year-old male, affected by chronic obstructive pulmonary disease, was diagnosed with fever, worsening of cough and chest pain on the left side. His past medical history was remarkable for chronic obstructive pulmonary disease. A chest X-ray showed a left upper lobe infiltrate consistent with a 
lung abscess. A sputum culture demonstrated P. aeruginosa resistant to ciprofloxacin. Intravenous antibiotic therapy with piperacillin/tazobactam was commenced, with improvement in the patient's clinical conditions and normalization of vital signs within 3 days.

\subsubsection{Intervention 8}

On day 3 of antibiotic therapy, the patient's clinical conditions greatly improved and his vital signs returned to normal limits. On day 7, a midline catheter was inserted and the patient was discharged. He was referred to an outpatient service to continue continuous infusion of piperacillin/tazobactam (18 g daily), administered through an elastomeric pump, for 5 weeks.

\subsubsection{Comment 8}

There is growing evidence that infusion pump (e.g., elastomeric pumps) use is an effective outpatient parenteral antibiotic therapy strategy to facilitate de-hospitalization, especially in patients treated with time-dependent antibiotics [27]. When antibiotics are delivered through elastomeric pumps, the individuals should be visited on an outpatient basis once a day for receiving the antibiotic solution reconstituted, bringing the infusion pump in a pouch. Indeed, this policy improves patient quality of life, allowing the possibility to continue normal life activities with scarce limitations. The use of elastomeric pumps cannot be completely assimilated to continuous infusions in hospitalized patients because of temperature issues (pumps are close to patients' skin), device materials and forced dilutions that could affect antibiotic stability. Moreover, the use of outpatients' infusion pumps requires at least a medium-term peripheral venous access (e.g., midline catheter). However, most antibiotics administered in continuous infusion in hospitalized patients also have evidence-based data from studies conducted with elastomeric pumps (Table 3). Before starting beta-lactams and vancomycin infusion, it is advisable to administer a loading dose in order to reduce time to reach target concentrations [28,29]. A list of antibiotics suitable for continuous infusion is furnished in Table 3.

Table 3. Common antimicrobials used for continuous infusion.

\begin{tabular}{|c|c|c|c|c|}
\hline Antibiotic & Stability at $25^{\circ} \mathrm{C}$ & Diluent & $\begin{array}{l}\text { Existing Data in } \\
\text { Elastomeric Pumps }\end{array}$ & References \\
\hline amoxicillin & $12 \mathrm{~h}$ & WFI/NS & Yes & [30] \\
\hline aztreonam & 48 & D5W & Yes & [32] \\
\hline Cefazolin * & $24 \mathrm{~h}$ & NS/D5W & Yes & [33-35] \\
\hline cefepime & $24 \mathrm{~h}$ & NS & Yes & {$[35,36]$} \\
\hline cefoxitin & $48 \mathrm{~h}$ & NS/D5W & Yes & [39] \\
\hline ceftaroline & $24 \mathrm{~h}$ & NS/D5W & Yes & [40] \\
\hline ceftazidime & $48 \mathrm{~h}$ & NS & Yes & {$[33,41]$} \\
\hline ceftazidime/avibactam & $12 \mathrm{~h}$ & NS/D5W/RL & Yes & [42] \\
\hline ceftolozane/tazobactam & $24 \mathrm{~h}$ & NS/D5W & Yes & [43] \\
\hline meropenem & $4 \mathrm{~h}$ & NS & Unsuitable (short stability) & [50] \\
\hline oxacillin & $24 \mathrm{~h}$ & NS & No & [51] \\
\hline benzylpenicillin potassium & $24-48 \mathrm{~h}$ & RA & Yes & {$[33,52]$} \\
\hline benzylpenicillin sodium & $12-24 \mathrm{~h}$ & NS & Yes & [53] \\
\hline piperacillin/tazobactam & $24 \mathrm{~h}$ & NS & Yes & [35] \\
\hline temocillin & $24 \mathrm{~h}$ & WFI & Yes & {$[54,55]$} \\
\hline vancomycin & $7 \mathrm{~d}$ & NS & Yes & [27] \\
\hline
\end{tabular}

* protect the reconstituted solution from sunlight; EP: elastomeric pumps; NS: normal saline; D5W: dextrose 5\% in water; RA: ringer acetate; RL: ringer lactate; WFI: water for injection. 


\subsection{ESBL or Carbapenem-Resistant Enterobacteriaceae (CRE) Urinary Tract Infections}

\subsubsection{Example 9}

A 74-year old man with relapsing urinary tract infections and benign prostatic hyperplasia was scheduled for transurethral biopsy of the prostate. One month before, he was treated for urinary tract infection; at that time, the urine culture grew 100,000 CFU/mL of ESBL-producing E. coli.

\subsubsection{Intervention 9}

Fosfomycin trometamol $3 \mathrm{~g}$ per os given once before bedtime the day before prostate biopsy was prescribed.

\subsubsection{Comment 9}

Fosfomycin trometamol has an excellent urinary concentration with mean peak urinary concentrations (within $4 \mathrm{~h}$ from administration) ranging from 1053 to $4415 \mathrm{mg} / \mathrm{L}$ after a single $3 \mathrm{~g}$ dose [56]. Such a high concentration is multiple times above the minimal inhibitory concentration of most urinary pathogens, making fosfomycin a good option for urinary tract infections, and also for those sustained by multi-drug resistant pathogens.

A recent systematic review of the studies on fosfomycin in comparison with fluoroquinolones to prevent trans-rectal ultrasound-guided prostate biopsy-related infectious complications showed that patients who received fosfomycin prophylaxis were less likely than those who received fluoroquinolone prophylaxis to develop infections overall, as well as severe and resistant infections. The difference was explained by fluoroquinolone resistance and ESBL production in pathogens causing post-biopsy infections. A retrospective study on 52 patients with urinary tract infections from ESBL-producing E. coli treated with fosfomycin trometamol $3 \mathrm{~g}$ per os every $48 \mathrm{~h} 3$ times reported a clinical and microbiological success rate of $94 \%$ and $78 \%$, respectively [57].

Apart from ESBL-producing bacteria, fosfomycin has been demonstrated to be a viable option for infections sustained by CRE. In fact, fosfomycin is active against approximately $80 \%$ of CRE, especially Klebsiella pneumoniae carbapenemase (KPC)-producing Klebsiella pneumoniae, including colistin-resistant strains [58], and represent an helpful drug from an AMS point of view.

\subsection{Biomarkers and Urinary Antigens as Stewardship Tools}

\subsubsection{Example 10}

A 65-year-old female patient with no previous medical history was diagnosed with communityacquired pneumonia. Intravenous ampicillin/sulbactam and clarithromycin were commenced. Urinary pneumococcal antigen tested positive.

\subsubsection{Intervention 10}

Clarithromycin was discontinued and ampicillin/sulbactam de-escalated to penicillin G.

\subsubsection{Comment 10}

Macrolides are overprescribed antibiotics and represent an easy target for AMS interventions. It has been demonstrated that the hospital rate of pneumococcal urinary antigen testing was strongly correlated with de-escalation following a positive test [59], suggesting that the use of urinary antigen testing could also be enforced in terms of an AMS viable tool. Regarding Streptococcus pneumoniae pneumonia, de-escalation to penicillin G is safe when penicillin G MIC in pneumococci $\leq 2 \mu \mathrm{g} / \mathrm{mL}$ (again we recommend relying on reliable local or national susceptibility testing data if the bacterial isolate has not grown). 


\subsubsection{Example 11}

A 50-year-old male affected by obesity and diabetes mellitus was admitted to an intensive care unit for sepsis with severe respiratory insufficiency. A diagnosis of influenza complicated by bacterial pulmonary superinfection due to Haemophilus influenzae was established. Procalcitonin on diagnosis was $10 \mu \mathrm{g} / \mathrm{L}$ (normal values $<0.5 \mu \mathrm{g} / \mathrm{L}$ ). After 5 days of oral oseltamivir and intravenous ampicillin/sulbactam, the patient experienced significant clinical amelioration and procalcitonin dropped to $0.5 \mu \mathrm{g} / \mathrm{L}$.

\subsubsection{Intervention 11}

Antibiotic therapy was stopped after 5 days.

\subsubsection{Comment 11}

Procalcitonin has been used as a tool to support clinical decisions on antibiotic discontinuation. A prospective, multicenter, randomized, controlled, open-label intervention trial compared two strategies in Dutch intensive care units. The authors included 761 patients in the procalcitonin-guided group and 785 patients in the standard-of-care group. In the procalcitonin-guided group, non-binding advice to discontinue antibiotics was provided if procalcitonin concentration had decreased by $80 \%$ or more of its peak value or to $0.5 \mu \mathrm{g} / \mathrm{L}$ or lower. The results show that the median duration of treatment was 5 days in the procalcitonin-guided vs 7 days in the standard-of-care-guided group $(p<0.0001)$ and this was also associated with a significantly reduced mortality in the procalcitonin-guided group ( $20 \%$ vs $27 \%$ [ $p=0.0154]$ in the per-protocol analysis) [60].

\subsection{Old Antibiotics Reuse}

\subsubsection{Example 12}

A 70-year-old man with history of nephrolithiasis and benign prostatic hyperplasia developed dysuria and high-grade fever accompanied by shaking chills. Urine culture grew $10^{6} \mathrm{CFU} / \mathrm{mL}$ of ESBL-producing K. pneumoniae. The strain was resistant to piperacillin/tazobactam (MIC $32 \mu \mathrm{g} / \mathrm{mL}$ ), and fosfomycin but susceptible to temocillin (MIC $4 \mu \mathrm{g} / \mathrm{mL}$ ).

\subsubsection{Intervention 12}

Intravenous temocillin: $2 \mathrm{~g}$ loading dose followed by $6 \mathrm{~g}$ in $24 \mathrm{~h}$ continuous infusion was started with progressive amelioration of clinical signs and symptoms and improvement of biochemical parameters.

\subsubsection{Comment 12}

Temocillin is a carboxypenicillin active against ESBL, KPC and AmpC-producing Enterobacteriaceae. It is a forgotten antibiotic, recently rediscovered and used for bacteremia, urinary tract infection and lower respiratory tract infection. The cumulative percentage of a $24 \mathrm{~h}$ period during which the free drug concentration exceeds the minimum inhibitory concentration (fT $>$ MIC) is the best pharmacokinetic/pharmacodynamic index [61]. The data showed that continuous infusion allows one to better target attainment compared to intermittent administration [54]. Temocillin is not commonly available in most developed countries, therefore we encourage efforts to procure/import the drug.

\subsection{Antibiotic Allergy De-Labelling}

\subsubsection{Example 13}

A 75-years old man underwent the removal of a shoulder prosthesis for a prosthetic joint infection six months previously. His postoperative course seemed to be uneventful, but he did not stop complaining of stress-induced and nocturnal resting pain, and poor mobility. Revision was 
performed with the removal of the prosthesis. Sonication fluid grew Cutibacterium acnes $100 \mathrm{CFU} / \mathrm{mL}$, and three out of four additional bone samples were positive for the same microorganism. The patient's medical history revealed an allergy to penicillin. The patient was started on ceftriaxone $2 \mathrm{~g}$ every $24 \mathrm{~h}$ intravenously.

\subsubsection{Intervention 13}

The patient was sent to allergology clinics and the immediate type of allergy to penicillin was excluded by skin test. After 14 days of parenteral therapy, the patient was switched to oral treatment with amoxicillin $1000 \mathrm{mg}$ every $8 \mathrm{~h}$ for additional 4 weeks.

\subsubsection{Comment 13}

Antibiotic allergy labels that reflect variable adverse drug reactions are found in 10-30\% of hospitalized patients. The labels lead to the substitution of antibiotics of choice with second line drugs that are often associated with microbial resistance, higher cost or even sub-optimal patient outcomes. Antibiotic allergy in-depth review has been shown to remove the label in more than $90 \%$ of cases, and may contribute to better antibiotic use [62]. De-labelling has been recommended as an antimicrobial stewardship strategy in Infectious Diseases Society of America guidelines [7].

\section{Discussion}

Antibiotic misuse or overuse is still highly prevalent in the hospital setting. Indeed, previous reports have shown that infectious disease specialist consultation can lead to resource-saving advices in more than $40 \%$ of cases [6]. The implementation of AMS programs has been advocated in order to counteract the increase in bacterial resistance and its related consequences [7]. While the general principles of AMS have long since been established, AMS programs are continuously evolving. This is partly a consequence of evolving scientific knowledge and the implementation of novel approaches to patient care. On the other hand, there are difficulties in increasing AMS programs' efficiency due to a gap between the theoretical benefits of selected interventions and their implementation in real life. An important limitation is given by the fact that AMS programs address general principles that may not be generalizable in all settings.

In our manuscript, we have described several clinical scenarios frequently occurring during routine clinical practice, and we have proposed targeted practical interventions to optimize antibiotic therapy. Each scenario elucidates how the main principles of AMS could be applied at a patient level. Narrowing the antibiotic spectrum (intervention 2) is the mainstay of correct antibiotic usage and, when correctly applied, has the potential to obtain clinical success while minimizing the risk of increasing resistance. It is strictly dependent on microbiological data such as a continuous monitoring of local resistance epidemiology, but also the development of methods for accurate and rapid identification of pathogens and characterization of their resistance profile [63]. Urinary antigen use could be useful for this purpose (intervention 10). Interestingly, narrowing the antibiotic spectrum can also be obtained in the management of selected uncomplicated infections caused by multi-drug-resistant (MDR) pathogens, such as ESBL or CRE urinary tract infections (intervention 9). In the setting of MDR, the re-use of old antibiotics should also be considered (intervention 12).

The optimal use of antibiotics can also be obtained by the optimization of dosage or administration modes on the basis of their pharmacokinetic/pharmacodynamics properties (intervention 1). A shift from intravenous to oral therapy when the patient is stable (interventions 4-5), especially to drugs with high oral bioavailability [64], is one of the interventions endorsed in AMS programs. Recently, a rapid shift to oral antibiotics has been proposed also for the management of selected endocarditis and bone/joints infections [18,19], conditions traditionally treated with long cycles of parenteral therapy. This approach can reduce the risk of phlebitis, intravenous line-associated infections and length of hospital stay. The latter can also be obtained by shortening antibiotic duration in scenarios characterized by rapid clinical response and source control (interventions 6-7), or with the aid of 
biomarker monitoring (i.e., procalcitonin) (intervention 11). In patients requiring long term antibiotic treatment, de-hospitalizing patients can be pursued by implementing outpatient antibiotic therapy services (intervention 8).

AMS programs should also take into account all scenarios characterized by antibiotic misuse. The double anaerobic coverage (intervention 3) is frequently observed in the management of intra-abdominal infections and should generally be avoided. Moreover, in patients with reported penicillin allergy, de-labelling is preferred over using a second-line drug, which is often a broad spectrum antibiotic with a higher impact on resistance spread (intervention 13).

\section{Conclusions}

In conclusion, we provided a series of real-life clinical scenarios in order to discuss the main current topics of AMS. The aim of the present manuscript was to furnish practical cues for physicians involved in the management of bacterial infections. Some of the interventions described are already well established and supported by a large volume of evidence, while the others are based on recently published studies and look promising for at least some patients. The evidence is expected to change over the time, and, to improve antibiotic prescribing, we need to include it meaningfully in our clinical practice. There is a role for AMS teams to introduce new evidence and promote the use of well-established practices, but at the same time every prescribing physician should improve his knowledge on up-to date antibiotic treatments in his field of expertise.

Author Contributions: S.D.B. conceived the study and wrote the manuscript; B.B., M.F. and M.V. reviewed the literature, R.L. wrote and reviewed the manuscript. All authors have read and agreed to the published version of the manuscript.

Funding: This research received no external funding.

Conflicts of Interest: The authors declare no conflict of interest.

\section{References}

1. Zellweger, R.M.; Carrique-Mas, J.; Limmathurotsakul, D.; Day, N.P.J.; Thwaites, G.E.; Baker, S. Southeast Asia antimicrobial resistance network a current perspective on antimicrobial resistance in Southeast Asia. J. Antimicrob. Chemother. 2017, 72, 2963-2972. [CrossRef] [PubMed]

2. Centers for Disease Control and Prevention (U.S.). Antibiotic Resistance Threats in the United States; Centres for Disease Control and Prevention: Atlanta, GA, USA, 2019.

3. Cassini, A.; Högberg, L.D.; Plachouras, D.; Quattrocchi, A.; Hoxha, A.; Simonsen, G.S.; Colomb-Cotinat, M.; Kretzschmar, M.E.; Devleesschauwer, B.; Cecchini, M.; et al. Attributable deaths and disability-adjusted life-years caused by infections with antibiotic-resistant bacteria in the EU and the European Economic Area in 2015: A population-level modelling analysis. Lancet Infect. Dis. 2019, 19, 56-66. [CrossRef]

4. Review on Antimicrobial Resistance. Antimicrobial Resistance: Tackling a Crisis for the Health and Wealth of Nations; Review on Antimicrobial Resistance: London, UK, 2014.

5. Schuts, E.C.; Hulscher, M.E.; Mouton, J.W.; Verduin, C.M.; Stuart, J.W.C.; Overdiek, H.W.; van der Linden, P.D.; Natsch, S.; Hertogh, C.M.; Wolfs, T.F.W.; et al. Current evidence on hospital antimicrobial stewardship objectives: A systematic review and meta-analysis. Lancet Infect. Dis. 2016, 16, 847-856. [CrossRef]

6. Fantoni, M.; Murri, R.; Scoppettuolo, G.; Fabbiani, M.; Ventura, G.; Losito, R.; Berloco, F.; Spanu, T.; Sanguinetti, M.; Cauda, R. Resource-saving advice from an infectious diseases specialist team in a large university hospital: An exportable model? Future Microbiol. 2015, 10, 15-20. [CrossRef]

7. Barlam, T.F.; Cosgrove, S.E.; Abbo, L.M.; MacDougall, C.; Schuetz, A.N.; Septimus, E.J.; Srinivasan, A.; Dellit, T.H.; Falck-Ytter, Y.T.; Fishman, N.O.; et al. Implementing an antibiotic stewardship program: Guidelines by the infectious diseases society of america and the society for healthcare epidemiology of America. Clin. Infect. Dis. 2016, 62, e51-e77. [CrossRef]

8. Dyar, O.J.; Huttner, B.; Schouten, J.; Pulcini, C.; ESGAP (ESCMID Study Group for Antimicrobial stewardshiP). What is antimicrobial stewardship? Clin. Microbiol. Infect. 2017, 23, 793-798. [CrossRef] 
9. Cunha, C.B. Antimicrobial stewardship programs: Principles and practice. Med. Clin. N. Am. 2018, 102, 797-803. [CrossRef]

10. Cooke, F.J.; Holmes, A.H. The missing care bundle: Antibiotic prescribing in hospitals. Int. J. Antimicrob. Agents 2007, 30, 25-29. [CrossRef]

11. Roberts, J.A.; Abdul-Aziz, M.-H.; Davis, J.S.; Dulhunty, J.M.; Cotta, M.O.; Myburgh, J.; Bellomo, R.; Lipman, J. Continuous versus intermittent $\beta$-Lactam infusion in severe sepsis. A Meta-analysis of Individual Patient Data from Randomized Trials. Am. J. Respir. Crit. Care Med. 2016, 194, 681-691. [CrossRef]

12. Magill, S.S.; Edwards, J.R.; Bamberg, W.; Beldavs, Z.G.; Dumyati, G.; Kainer, M.A.; Lynfield, R.; Maloney, M.; McAllister-Hollod, L.; Nadle, J.; et al. Multistate point-prevalence survey of health care-associated infections. N. Engl. J. Med. 2014, 370, 1198-1208. [CrossRef]

13. Owens, R.C., Jr.; Donskey, C.J.; Gaynes, R.P.; Loo, V.G.; Muto, C.A. Antimicrobial-associated risk factors for Clostridium difficile infection. Clin. Infect. Dis. 2008, 46, S19-S31. [CrossRef] [PubMed]

14. Skrlin, J.; Bacic Vrca, V.; Marusic, S.; Ciric-Crncec, M.; Mayer, L. Impact of ceftriaxone de-restriction on the occurrence of ESBL-positive bacterial strains and antibiotic consumption. J. Chemother. 2011, 23, 341-344. [CrossRef]

15. Song, Y.J.; Kim, M.; Huh, S.; Lee, J.; Lee, E.; Song, K.-H.; Kim, E.S.; Kim, H.B. Impact of an antimicrobial stewardship program on unnecessary double anaerobic coverage prescription. Infect. Chemother. 2015, 47, 111-116. [CrossRef] [PubMed]

16. Hecker, M.T.; Aron, D.C.; Patel, N.P.; Lehmann, M.K.; Donskey, C.J. Unnecessary use of antimicrobials in hospitalized patients. Arch. Intern. Med. 2003, 163, 972. [CrossRef] [PubMed]

17. Brook, I.; Wexler, H.M.; Goldstein, E.J.C. Antianaerobic antimicrobials: Spectrum and susceptibility testing. Clin. Microbiol. Rev. 2013, 26, 526-546. [CrossRef] [PubMed]

18. Iversen, K.; Ihlemann, N.; Gill, S.U.; Madsen, T.; Elming, H.; Jensen, K.T.; Bruun, N.E.; Høfsten, D.E.; Fursted, K.; Christensen, J.J.; et al. Partial Oral versus intravenous antibiotic treatment of endocarditis. N. Engl. J. Med. 2019, 380, 415-424. [CrossRef]

19. Li, H.-K.; Rombach, I.; Zambellas, R.; Walker, A.S.; McNally, M.A.; Atkins, B.L.; Lipsky, B.A.; Hughes, H.C.; Bose, D.; Kümin, M.; et al. Oral versus intravenous antibiotics for bone and joint infection. N. Engl. J. Med. 2019, 380, 425-436. [CrossRef]

20. Yahav, D.; Franceschini, E.; Koppel, F.; Turjeman, A.; Babich, T.; Bitterman, R.; Neuberger, A.; Ghanem-Zoubi, N.; Santoro, A.; Eliakim-Raz, N.; et al. Seven Versus 14 days of antibiotic therapy for uncomplicated gram-negative bacteremia: A noninferiority randomized controlled trial. Clin. Infect. Dis. 2019, 69, 1091-1098. [CrossRef]

21. Gjika, E.; Beaulieu, J.-Y.; Vakalopoulos, K.; Gauthier, M.; Bouvet, C.; Gonzalez, A.; Morello, V.; Steiger, C.; Hirsiger, S.; Lipsky, B.A.; et al. Two weeks versus four weeks of antibiotic therapy after surgical drainage for native joint bacterial arthritis: A prospective, randomised, non-inferiority trial. Ann. Rheum. Dis. 2019, 78, 1114-1121. [CrossRef]

22. Athlin, S.; Lidman, C.; Lundqvist, A.; Naucler, P.; Nilsson, A.C.; Spindler, C.; Strålin, K.; Hedlund, J. Management of community-acquired pneumonia in immunocompetent adults: Updated Swedish guidelines 2017. Infect. Dis. 2018, 50, 247-272. [CrossRef]

23. National Institute for Health and Care Excellence. Pneumonia in Adults: Diagnosis and Management; National Institute for Health and Care Excellence: London, UK, 2020.

24. Chastre, J.; Wolff, M.; Fagon, J.-Y.; Chevret, S.; Thomas, F.; Wermert, D.; Clementi, E.; Gonzalez, J.; Jusserand, D.; Asfar, P.; et al. Comparison of 8 vs. 15 days of antibiotic therapy for ventilator-associated pneumonia in adults: A randomized trial. JAMA 2003, 290, 2588-2598. [CrossRef] [PubMed]

25. Coplen, D.E. Executive summary: International clinical practice guidelines for the treatment of acute uncomplicated cystitis and pyelonephritis in women: A 2010 update by the infectious diseases society of america and the european society for microbiology and infectious diseases. Yearb. Urol. 2011, 2011, 240-241.

26. Sawyer, R.G.; Claridge, J.A.; Nathens, A.B.; Rotstein, O.D.; Duane, T.M.; Evans, H.L.; Cook, C.H.; O’Neill, P.J.; Mazuski, J.E.; Askari, R.; et al. Trial of short-course antimicrobial therapy for intraabdominal infection. N. Engl. J. Med. 2018, 378, 686. [CrossRef] 
27. Voumard, R.; Gardiol, C.; André, P.; Arensdorff, L.; Cochet, C.; Boillat-Blanco, N.; Decosterd, L.; Buclin, T.; de Vallière, S. Efficacy and safety of continuous infusions with elastomeric pumps for outpatient parenteral antimicrobial therapy (OPAT): An observational study. J. Antimicrob. Chemother. 2018, 73, 2540-2545. [CrossRef] [PubMed]

28. Waineo, M.F.; Kuhn, T.C.; Brown, D.L. The pharmacokinetic/pharmacodynamic rationale for administering vancomycin via continuous infusion. J. Clin. Pharm. Ther. 2015, 40, 259-265. [CrossRef] [PubMed]

29. Roberts, J.A.; Kirkpatrick, C.M.J.; Roberts, M.S.; Dalley, A.J.; Lipman, J. First-dose and steady-state population pharmacokinetics and pharmacodynamics of piperacillin by continuous or intermittent dosing in critically ill patients with sepsis. Int. J. Antimicrob. Agents 2010, 35, 156-163. [CrossRef] [PubMed]

30. Binson, G.; Grignon, C.; Le Moal, G.; Lazaro, P.; Lelong, J.; Roblot, F.; Venisse, N.; Dupuis, A. Overcoming stability challenges during continuous intravenous administration of high-dose amoxicillin using portable elastomeric pumps. PLoS ONE 2019, 14, e0221391. [CrossRef]

31. Herrera-Hidalgo, L.; López-Cortes, L.E.; Luque-Márquez, R.; Gálvez-Acebal, J.; de Alarcón, A.; López-Cortes, L.F.; Gutiérrez-Valencia, A.; Gil-Navarro, M.V. Ampicillin and ceftriaxone solution stability at different temperatures useful for outpatient parenteral antimicrobial therapy (OPAT). Antimicrob. Agents Chemother. 2020. [CrossRef]

32. Burgess, D.S.; Summers, K.K.; Hardin, T.C. Pharmacokinetics and pharmacodynamics of aztreonam administered by continuous intravenous infusion. Clin. Ther. 1999, 21, 1882-1889. [CrossRef]

33. Tice, A.D.; Rehm, S.J.; Dalovisio, J.R.; Bradley, J.S.; Martinelli, L.P.; Graham, D.R.; Gainer, R.B.; Kunkel, M.J.; Yancey, R.W.; Williams, D.N.; et al. Practice guidelines for outpatient parenteral antimicrobial therapy. IDSA guidelines. Clin. Infect. Dis. 2004, 38, 1651-1672. [CrossRef]

34. Patel, R.P.; Jacob, J.; Sedeeq, M.; Ming, L.C.; Wanandy, T.; Zaidi, S.T.R.; Peterson, G.M. Stability of cefazolin in polyisoprene elastomeric infusion devices. Clin. Ther. 2018, 40, 664-667. [CrossRef] [PubMed]

35. Voumard, R.; Van Neyghem, N.; Cochet, C.; Gardiol, C.; Decosterd, L.; Buclin, T.; de Valliere, S. Antibiotic stability related to temperature variations in elastomeric pumps used for outpatient parenteral antimicrobial therapy (OPAT). J. Antimicrob. Chemother. 2017, 72, 1462-1465. [CrossRef] [PubMed]

36. Huang, H.; Huang, S.; Zhu, P.; Xi, X. Continuous versus intermittent infusion of cefepime in neurosurgical patients with post-operative intracranial infections. Int. J. Antimicrob. Agents 2014, 43, 68-72. [CrossRef]

37. Available online: http://products.sanofi.ca/en/claforan.pdf (accessed on 8 December 2019).

38. Available online: http://www.just.edu.jo/DIC/DrugsLibrary/Cefotaxime.pdf (accessed on 8 December 2019).

39. Cavalli, Z.; Becker, A.; Bosch, A.; Conrad, A.; Triffault-Filit, C.; Valour, F.; Laurent, F.; Cohen, S.; Chidiac, C.; Ferry, T. Prolonged cefoxitin infusion using mobile elastomeric infusors in outpatients with bone and joint infection. J. Bone Jt. Infect. 2018, 3, 182-186. [CrossRef] [PubMed]

40. Madfai, F.A.; Al Madfai, F.; Zaidi, S.T.R.; Ming, L.C.; Wanandy, T.; Patel, R.P. Physical and chemical stability of ceftaroline in an elastomeric infusion device. Eur. J. Hosp. Pharm. 2018, 25, e115-e119. [CrossRef] [PubMed]

41. Jones, T.E.; Selby, P.R.; Mellor, C.S.; Cheam, D.B. Ceftazidime stability and pyridine toxicity during continuous i.v., infusion. Am. J. Health Syst. Pharm. 2019, 76, 200-205. [CrossRef]

42. Torres-Del-Pliego, E.; Delgado-Mejía, E.; Gil-Alonso, L.; Del Mar-Periáñez-Párraga, L. First case of ceftazidime/avibactam administration in home care. ESBL producing Klebsiella pneumoniae bacteremia. Enferm. Infecc. Microbiol. Clin. 2017, 35, 322-323. [CrossRef]

43. Terracciano, J.; Rhee, E.G.; Walsh, J. Chemical stability of ceftolozane/tazobactam in polyvinylchloride bags and elastomeric pumps. Curr. Ther. Res. Clin. Exp. 2017, 84, 22-25. [CrossRef]

44. Stiles, M.L.; Allen, L.V., Jr.; Fox, J.L. Stability of ceftazidime (with arginine) and of cefuroxime sodium in infusion-pump reservoirs. Am. J. Hosp. Pharm. 1992, 49, 2761-2764. [CrossRef]

45. Vercheval, C.; Streel, S.; Servais, A.-C.; Fillet, M.; Van Hees, T. Stability of $90 \mathrm{mg} / \mathrm{mL}$ cefuroxime sodium solution for administration by continuous infusion. J. Chemother. 2018, 30, 371-374. [CrossRef]

46. Zeller, V.; Dzeing-Ella, A.; Kitzis, M.-D.; Ziza, J.-M.; Mamoudy, P.; Desplaces, N. Continuous clindamycin infusion, an innovative approach to treating bone and joint infections. Antimicrob. Agents Chemother. 2010, 54, 88-92. [CrossRef] [PubMed]

47. Howden, B.P.; Richards, M.J. The efficacy of continuous infusion flucloxacillin in home therapy for serious staphylococcal infections and cellulitis. J. Antimicrob. Chemother. 2001, 48, 311-314. [CrossRef] 
48. Fomicyt $40 \mathrm{mg} / \mathrm{mL}$ Powder for Solution for Infusion-100mL Bottle-Summary of Product Characteristics (SmPC)—(emc). Available online: https://www.medicines.org.uk/emc/product/5439/smpc (accessed on 7 December 2019).

49. Asuphon, O.; Montakantikul, P.; Houngsaitong, J.; Kiratisin, P.; Sonthisombat, P. Optimizing intravenous fosfomycin dosing in combination with carbapenems for treatment of Pseudomonas aeruginosa infections in critically ill patients based on pharmacokinetic/pharmacodynamic (PK/PD) simulation. Int. J. Infect. Dis. 2016, 50, 23-29. [CrossRef] [PubMed]

50. Foy, F.; Luna, G.; Martinez, J.; Nizich, Z.; Seet, J.; Lie, K.; Sunderland, B.; Czarniak, P. An investigation of the stability of meropenem in elastomeric infusion devices. Drug Des. Dev. Ther. 2019, 13, 2655-2665. [CrossRef] [PubMed]

51. Nesseler, N.; Verdier, M.-C.; Launey, Y.; Malherbe, A.; Dermu, M.; Piau, C.; Flécher, E.; Tribut, O.; Mallédant, Y.; Seguin, P. High-dose continuous oxacillin infusion results in achievement of pharmacokinetics targets in critically ill patients with deep sternal wound infections following cardiac surgery. Antimicrob. Agents Chemother. 2014, 58, 5448-5455. [CrossRef] [PubMed]

52. Nakamura, T.; Enoki, Y.; Uno, S.; Uwamino, Y.; Iketani, O.; Hasegawa, N.; Matsumoto, K. Stability of benzylpenicillin potassium and ampicillin in an elastomeric infusion pump. J. Infect. Chemother. 2018, 24, 856-859. [CrossRef]

53. Vella-Brincat, J.W.A.; Begg, E.J.; Gallagher, K.; Kirkpatrick, C.M.J.; Zhang, M.; Frampton, C.; Chambers, S.T. Stability of benzylpenicillin during continuous home intravenous therapy. J. Antimicrob. Chemother. 2004, 53, 675-677. [CrossRef]

54. Laterre, P.-F.-F.; Laterre, P.; Wittebole, X.; Van de Velde, S.; Muller, A.E.; Mouton, J.W.; Carryn, S.; Tulkens, P.M.; Dugernier, T. Temocillin (6 g daily) in critically ill patients: Continuous infusion versus three times daily administration. J. Antimicrob. Chemother. 2015, 70, 891-898. [CrossRef]

55. Carryn, S.; Couwenbergh, N.; Tulkens, P.M. Long-term stability of temocillin in elastomeric pumps for outpatient antibiotic therapy in cystic fibrosis patients. J. Antimicrob. Chemother. 2010, 65, 2045-2046. [CrossRef]

56. Patel, S.S.; Balfour, J.A.; Bryson, H.M. Fosfomycin tromethamine. A review of its antibacterial activity, pharmacokinetic properties and therapeutic efficacy as a single-dose oral treatment for acute uncomplicated lower urinary tract infections. Drugs 1997, 53, 637-656. [CrossRef]

57. Roberts, M.J.; Scott, S.; Harris, P.N.; Naber, K.; Wagenlehner, F.M.; Doi, S.A. Comparison of fosfomycin against fluoroquinolones for transrectal prostate biopsy prophylaxis: An individual patient-data meta-analysis. World J. Urol. 2018, 36, 323-330. [CrossRef]

58. Durante-Mangoni, E.; Andini, R.; Zampino, R. Management of carbapenem-resistant Enterobacteriaceae infections. Clin. Microbiol. Infect. 2019, 25, 943-950. [CrossRef] [PubMed]

59. Schimmel, J.J.; Haessler, S.; Imrey, P.; Lindenauer, P.K.; Richter, S.S.; Yu, P.-C.; Rothberg, M.B. Pneumococcal urinary antigen testing in US hospitals: A missed opportunity for antimicrobial stewardship. Clin. Infect. Dis. 2019. [CrossRef]

60. De Jong, E.; van Oers, J.A.; Beishuizen, A.; Vos, P.; Vermeijden, W.J.; Haas, L.E.; Loef, B.G.; Dormans, T.; van Melsen, G.C.; Kluiters, Y.C.; et al. Efficacy and safety of procalcitonin guidance in reducing the duration of antibiotic treatment in critically ill patients: A randomised, controlled, open-label trial. Lancet Infect. Dis. 2016, 16, 819-827. [CrossRef]

61. Alexandre, K.; Fantin, B. Pharmacokinetics and pharmacodynamics of temocillin. Clin. Pharmacokinet. 2018, 57, 287-296. [CrossRef]

62. Trubiano, J.A.; Beekmann, S.E.; Worth, L.J.; Polgreen, P.M.; Thursky, K.A.; Slavin, M.A.; Grayson, M.L.; Phillips, E.J. Improving antimicrobial stewardship by antibiotic allergy delabeling: Evaluation of knowledge, attitude, and practices throughout the emerging infections network. Open Forum Infect. Dis. 2016, 3, ofw153. [CrossRef] [PubMed] 
63. Timbrook, T.T.; Morton, J.B.; McConeghy, K.W.; Caffrey, A.R.; Mylonakis, E.; LaPlante, K.L. The Effect of molecular rapid diagnostic testing on clinical outcomes in bloodstream infections: A systematic review and meta-analysis. Clin. Infect. Dis. 2017, 64, 15-23. [CrossRef] [PubMed]

64. Berbari, E.F.; Kanj, S.S.; Kowalski, T.J.; Darouiche, R.O.; Widmer, A.F.; Schmitt, S.K.; Hendershot, E.F.; Holtom, P.D.; Huddleston, P.M.; Petermann, G.W.; et al. 2015 Infectious Diseases Society of America (IDSA) Clinical practice guidelines for the diagnosis and treatment of native vertebral osteomyelitis in adults. Clin. Infect. Dis. 2015, 61, e26-e46. [CrossRef]

(C) 2020 by the authors. Licensee MDPI, Basel, Switzerland. This article is an open access article distributed under the terms and conditions of the Creative Commons Attribution (CC BY) license (http://creativecommons.org/licenses/by/4.0/). 